\title{
Controversies about the treatment of myasthenia gravis
}

\author{
LEW IS P ROWLAND
}

From the Department of Neurology, Columbia University College of Physicians and Surgeons; Neurological Service Presbyterian Hospital; H. Houston Merritt Clinical Research Center for Muscular Dystrophy and Related Diseases; Columbia-Presbyterian Medical Center

SUMMARY Clinicians treating patients with myasthenia gravis must choose cholinergic drugs, corticosteroids, immunosuppersive drugs, thymectomy, or plasmapheresis. Clinicians must decide the sequence or combination of these therapies and when to deem lack of improvement a sign for a different therapeutic approach. Because controlled trials have not been done to evaluate therapies that may require months or years before benefit is evident, controversy abounds.

It is a privilege to participate in this Festschrift to honour Ian Simpson who has shown us the power of clinical thought in analysing a medical disorder as a biological problem. Among his many contributions, he has been widely applauded for his studies of myasthenia gravis, including an early analysis of thymectomy, ${ }^{1}$ his introduction of the concept of myasthenia as an autoimmune disease, ${ }^{2}$ and the critical notion that pharmacological deductions about the physiological abnormality in myasthenia presumed normal morphological geometry at the endplate. ${ }^{3}$ Simultaneously with Simpson's closely reasoned arguments, Nastuk and Strauss and their colleagues provided the first evidence of humoral abnormality ${ }^{4}$ and AG Engel and his colleagues provided evidence that the morphology of the endplate is not normal in human myasthenia. ${ }^{5}$

It is my assignment in this symposium to review controversies about the therapy of myasthenia. Controversy is the unwanted child of ignorance, and we may be ignorant because we do not have the means to find the answers to questions, or because we have the means but cannot apply them. Too often in medicine, our ignorance seems to be due to asthenia of the will. We know how to find the answers, but we do not. We know that we could find out whether this or that proposed treatment is effective by setting up a controlled trial. But patients are not rabbits. Patients want to be treated and physicians have

Address for reprint requests: LP Rowland, MD, Neurological Institute 710 West 168th Street, New York 10032, USA.

Supported by Center grants from the Muscular Dystrophy Association, Inc. and the National Institute of Neurological and Communicative Diseases and Stroke (NS - 11766) their own emotional problems; they want to treat. We adopt therapeutic programmes because they seem logical or useful, and these therapies become so embedded in custom that it is ultimately deemed unethical to even consider a controlled trial.

We are not alone in this dilemma. When I was a medical student, standard treatments included vagotomy for peptic ulcer and sympathectomy for hypertension; current controversies include radical mastectomy, tonsillectomy, carotid endarterectomy, and coronary by-pass surgery. $^{6}{ }^{7}$ Nevertheless, when physicians are entrusted with the care of patients with myasthenia gravis, they must choose between cholinergic drugs, steroids, more specific immunosuppressive drugs, plasmapheresis, and thymectomy. There is uncertainty about the value of all of these and there is difference of opinion about specific details of each therapy, or the sequence to be chosen. Lacking appropriate evidence, the physician must nevertheless make a choice.

That is the dilemma. Recognising that there are differences of opinion, I will try to make the questions clear, and to provide fair statements of divergent views. I have my own views, of course, but will try to separate assertion from fact.

CHOLINERGIC DRUGS

Little attention is being paid to cholinergic drug therapy for at least two reasons: First, these drugs do not ordinarily restore normal life to patients with myasthenia. Second, the apparent clinical benefit of immunotherapies and evidence 
of abnormal immune mechanisms in the disease have shifted therapeutic attention to measures that might alter the course of the disease, rather than merely reversing symptoms. Reviving archaic debates may not seem appropriate but almost all clinicians use anticholinesterase inhibitors to start treatment, and it may be useful to indicate that there are still unanswered questions, even about this primeval form of drug therapy. Which anticholinesterase medication is most effective? The immediate effects of cholinergic drugs are so dramatic that the therapeutic response can be considered part of the definition of the disease. ${ }^{8}$ There is no need for a controlled trial when ptosis disappears before your very eyes or ophthalmoplegia melts into normal motion. The therapeutic benefit of oral medication, however, is usually much less dramatic. Some disabled patients may be returned to normal activity, but symptoms are rarely relieved completely. Of the three drugs now available (neostigmine, pryridostigmine, ambenonium), pyridostigmine has proven the most popular, but this choice was never based on any kind of formal assessment. Rather, patients were asked which drug they preferred, and most chose pyridostigmine because it caused the fewest gastrointestinal effects. There has never been convincing evidence that one drug is better than another for specific symptoms, or that one drug can be effective when another is not.

How is the optimal dosage of a cholinergic drug determined? There is still no way to determine the optimal dosage of pyridostigmine therapy, except by a trial that depends upon subjective responses of patient and physician. Osserman ${ }^{8}$ introduced the edrophonium test to determine optimal dosage. A patient already taking oral medication is given $2.0 \mathrm{mg}$ edrophonium intravenously. If symptoms improve, the patient is deemed undertreated and the oral dosage is increased. If symptoms worsen, overtreatment is presumed and the oral dosage is decreased. If edrophonium has no effect, oral treatment is deemed optimal.

However, the edrophonium test has never been assessed formally, to determine whether these conclusions are justified. It was never demonstrated why $2.0 \mathrm{mg}$ should be the decisive dose, rather than 3.0 or 5.0 or some other quantity, or why it should be the same in every patient. In untreated patients the same dose of edrophonium may have a diagnostic effect one day, no effect the next, or may improve function of some muscles but worsen others; how then can the test be reliable in treated patients? We never assessed this test formally either, but we have not found it a reliable guide to oral therapy, and the test does not seem to be used very often nowadays.

If there is no objective way to determine optimal dosage, we have to rely upon statements of the patient about the response of specific symptoms. It is my impression that patients and physicians tend to increase the dosage progressively, so long as the patient is not too distressed by side-effects. Often, the dosage can be sharply reduced without ill effect. Although there is no direct evidence to support the statement, few patients seem to show objective benefit from doses larger than $120 \mathrm{mg}$ every two or three hours. That is why "pyridostigmine requirement", at least in terms of daily dosage, should not be used as a measure of therapeutic effect for thymectomy or other measures designed to alter the course of myasthenia.

How often does cholinergic crisis occur? Years ago, when irreversible inhibitors of cholinesterase were evaluated in the treatment of myasthenia, it became apparent that overdosage could cause weakness and pyridine-aldoxine methiodide (PAM) was introduced as a specific antidote for this kind of organophosphate intoxication. That cholinergic crisis may occur is indisputable, and it can be demonstrated experimentally, ${ }^{9}$ but it is not clear whether or how often it occurs in patients treated with the standard drugs now in use. Indeed, as crisis itself has become less frequent, the question has disappeared from the literature.

There are still, however, occasional references to the use of edrophonium as a method to determine whether weakness is "myasthenic" or "cholinergic". As originally described, ${ }^{8}$ the test again required an arbitrary dosage of edrophonium $(1.0$ or $2.0 \mathrm{mg})$, but interpretation now depended on only two choices: if weakness improved, it was "myasthenic"; if there was no improvement, or if weakness worsened, the weakness was "cholinergic". Again, however, this interpretation was never assessed formally, and it is not clear why "no response" should be deemed optimal in one situation but not in another. We have been sceptical about this interpretation because it has been standard practice in our institution for 30 years to discontinue cholinergic medication whenever a patient requires respiratory support. Never have we seen a patient improve immediately after discontinuing cholinergic medication; either there is no immediate change, or, more often, the weakness becomes perceptibly worse. If cholinergic crisis 
occurred, patients should improve promptly when the drug is withdrawn. There has been no convincing documentation of acute cholinergic crisis in any patient taking only oral medication. Should administration of cholinergic drugs be discontinued during crisis? We define crisis as an exacerbation of myasthenic symptoms that requires mechanical ventilation. In 1949, Randt and Korey gave one patient $18.0 \mathrm{mg}$ neostigmine intravenously in one hour; the equivalent oral dose would be $440 \mathrm{mg}$ or almost 30 standard tablets of $15 \mathrm{mg}$ each. Within 60 hours, that patient received $50 \mathrm{mg}$ neostigmine intravenously and $95 \mathrm{mg}$ initramuscularly. ${ }^{10}$ There were neither beneficial nor deleterious effects but they concluded that cholinergic drug therapy could not terminate crisis, and continued use could complicate management by causing diarrhoea or increasing pulmonary secretions. For these reasons, it has become standard practice in our institution and others to discontinue cholinergic drug therapy as soon as mechanical ventilation is started.

One practical effect of this approach is that the distinction between "cholinergic" and "myasthenic" crisis becomes inconsequential, since the possibly offending drug is withdrawn anyway. It does, however, leave the question of when to resume drug therapy, and this is important after thymectomy as after crisis of other cause. There are no clear answers to this question but we view crisis as a temporary exacerbation; it is our task to keep the patient alive until the cause of the exacerbation subsides, assuming that it is due to transient effects of respiratory infection, aspiration pneumonitis, or surgery. Therefore, pyridostigmine does not seem useful and we cannot "get the patient off the respirator with pyridostigmine" while the patient is febrile, or while other complications are overtly active. Once these complications subside, respiration begins to improve and pyridostigmine can be started again.

Could treatment be improved by monitoring blood levels of cholinergic drugs? Little is known about the pharmacokinetics of pyridostigmine. After intravenous injection of ${ }^{14} \mathrm{C}$-labelled drug, $44-47 \%$ of the administered label appeared in the urine within one hour. ${ }^{11}$ Because excretion of the drug exceeded creatinine excretion, there seemed to be tubular excretion as well as glomerular filtration. ${ }^{12}{ }^{13}$ Interactions with other drugs and hepatic metabolism have not been defined, and much of orally administered drug appears in the faeces. ${ }^{13}$

There have been few studies of blood levels since the introduction of gas-liquid chromato- graphy. In one study, ${ }^{14}$ serum levels were lower in patients deemed "poorly controlled" than in those who seemed to be responding to therapy. Because parenteral administration of drug raised the low blood levels to the range of those in good control, the originally low drug levels were attributed to malabsorption. However, in another study, ${ }^{15}$ plasma pyridostigmine content was restricted to a narrow range $(20-60 \mathrm{mg} / \mathrm{ml})$ despite wide variations in daily dosage $(60-660 \mathrm{mg})$ among different patients. In still another study, peak levels and area under the curve were higher in poorly controlled patients. ${ }^{16}$ Further work seems to be necessary to resolve these differences, and to indicate whether therapeutic drug monitoring has a role in myasthenia.

Does chronic administration of cholinergic drugs have deleterious effects? From time to time, clinicians wonder whether patients may become "refractory" to the beneficial effects of cholinergic drugs, perhaps because of desensitisation of receptors or because of drug-induced changes in morphology. Experimentally, chronic administration of these drugs can induce both physiological and morphological changes. ${ }^{17-20}$ However, there is virtually no evidence that this is true in humans. The dosages used in the animals were much larger than patients take, and there is no clinical evidence of declining effect of cholinergic drugs that might be dependent upon dosage or duration of treatment (but that has not been assessed formally either). Mayer et $a^{21}$ presented evidence that myasthenic crisis might be due to drug-induced changes, but questions were raised about their data. ${ }^{21}$ The possibly beneficial effects of a "drug holiday" in treatment of myasthenic crisis have not been evaluated.

\section{THYMECTOMY}

Is thymectomy effective in the treatment of myasthenia? The world over, thymectomy is standard therapy for myasthenia. There is no debate about that statement. Yet the beneficial effects of thymectomy were discovered by accident when Blalock ${ }^{22}$ removed a cystic thymoma from a young woman with myasthenia, and the myasthenic symptoms subsequently improved. On the basis of that experience, the operation was gradually adopted, in large part due to the influential work of John Simpson. ${ }^{1}$ But in those days shortly after World War II, no one knew the function of the thymus, so there was not much rationale for thymectomy. Even today, it is not known whether benefit is bestowed because a source of antibodies is removed, 
because the source of antigen is removed, or for some other reason.

In the early days, there was controversy about the therapeutic value of thymectomy, and the considerable operative mortality was a restraint. Even at the Massachusetts General Hospital, six of the first ten thymectomies ended in death. ${ }^{23}$ But, Keynes ${ }^{24}$ soon pointed out that results were better for patients who lacked thymoma, and gradually improvements in surgery, anaesthesia, and respiratory care reduced the mortality rate to virtually nil. For instance, at the ColumbiaPresbyterian Medical Center, there were four deaths in 21 operations between, 1942 and 1955, but there were no deaths in 33 operations between 1956 and 1966, ${ }^{25}$ and there have been no deaths in 101 trans-sternal thymectomies from 1963 to $1979 .{ }^{26}$ Other centres have experienced the same changes; as the risks declined, more operations were done.

Results of the modern operation have been summarised in many reports since $1970^{27-46}$ and the generally held view can be stated succinctly. When there is no thymoma, thymectomy is followed by improvement in $66 \%$ to $86 \%$ of the patients. There has not really been much debate about this; McQuillen ${ }^{47} 48$ is a brave but solitary voice, questioning the nature of the Emperor Thymectomy's robes, and McQuillen's doubts were expressed by comparing only the incidence of complete remission in operated and unoperated cases. It may not be appropriate to disregard improvement short of complete remission, and some ${ }^{35}$ have questioned McQuillen's acceptance of possibly brief and early remissions in unoperated cases, in contrast to lasting remissions after thymectomy.

Whether McQuillen is absolutely correct or not, other students have been disquieted by the lack of any prospectively controlled study of thymectomy. Although several authors compared results in operated and unoperated cases, only one study was concerned with matched cases, comparing patients of the same age, sex, duration of symptoms, and sevenity of symptoms. ${ }^{27}$ Even in that study, operated and unoperated patients were not contemporary; operations were probably done more often in recent years, after improvements in respiratory care (and also after the introduction of steroid therapy).

Therefore, despite the almost universal belief in the efficacy of thymectomy, its value has not really been proven. Also, there have been some inexplicable cases, such as improvement of myasthenia after mediastinal exploration without thymectomy, ${ }^{49}$ or after removal of an echinococcus cyst of the lung. ${ }^{50}$ Some have even claimed that Blalock's original case was not really a thymectomy, because the tumor was entirely cystic. ${ }^{38}$ It is possible, though doubted by most, that improvement in respiratory care now permits patients to live after crisis that would have been fatal years ago, and that the natural history of the disease is then one of improvement. Simpson, ${ }^{51}$ Genkins et $a l,{ }^{52}$ and others believe that the disease is "active" for a finite time, although there is no way to measure "activity" of the disease except by symptoms. These possible doubts come rather late in the game and it is now difficult to conceive of a prospectively controlled trial of thymectomy, but some investigators in the USA are making the attempt.

Is cervical thymectomy preferable to transsternal thymectomy? Barring the nagging but fundamental doubts of McQuillen, the major controversy about thymectomy concerns the operative technique. The standard operation involves splitting the sternum and although operative mortality has been essentially obliterated, it is still a major operation; respiratory assistance is often required in the postoperative period and patients may have to remain in an intensive care unit for several days. It was therefore of great interest, in 1967, when Kark and Papatestas and their associates began to write about transcervical thymectomy. ${ }^{33415354}$ The morbidity of this procedure is much less than the transsternal operation and it spares the patients from a disfiguring scar on the chest. The morbidity is so slight that the indications can be extended to children or the elderly, or to patients with only slight functional disability, groups not ordinarily selected for the trans-sternal operation.

Since the results of the transcervical operation are claimed to be equivalent to the standard procedure, ${ }^{33415354}$ it is rather strange that the operation has not been adopted by more than one centre in the US and one in Europe. ${ }^{36}$ The major argument against the cervical approach has been stated by Jaretzki ${ }^{26}$; it is not possible to do a total thymectomy through the neck in every patient; complete removal of the thymus requires thorough exploration of the mediastinum. ${ }^{55}$ Several other arguments have been adduced: (1) There has been no prospective comparison of the two operations and more patients with mild myasthenia (who might be expected to have a better prognosis anyhow) are selected for the transcervical operation; outcomes of mild and severe cases operated in different epochs cannot be compared. (2) The cervical operation 
was introduced in 1967 and insufficient numbers of patients have been followed long enough for evaluation. (3) Takahashi et $a l^{46}$ reported remissions or improvement in $54 \%$ of 13 patients four years after cervical thymectomy performed between 1969 and 1973. For reasons similar to Jaretzki's ${ }^{56}$ they changed to a trans-sternal operation in 1973 and among 43 patients who had this "radical" operation, the rate of remission and improvement was $88.4 \%$ at four years, and improvement was seen sooner. (4) Even the proponents of the cervical operation believe the sternum should be split to remove thymomas, but not all thymic tumors are detected before surgery by standard radiograms (and computed tomography of the mediastinum may be falsely "positive"). ${ }^{57}$ (5) If the sternal operation is "thorough", it is known that all recognisable glandular tissue has been removed. If the patien! does not improve after cervical thymectomy, however, physicians may wonder about residual thymus. For instance, Stump et al ${ }^{58}$ reported that residual thymic tissue was found by a transsternal operation in all of five patients who had not improved after an earlier cervical thymectomy. Even the trans-sternal operation may leave tissue behind. ${ }^{26} 59$

This dispute will only be resolved by the results. What is needed is some evaluation of truly comparable patients subjected to the two procedures and followed for a prolonged period of observation; this is not available. If the cervical operation ultimately proves to be beneficial, it would mean that "total" thymectomy is not necessary for therapeutic effect. This conclusion is not impossible, since no one knows what deleterious influence is removed by thymectomy, nor why improvement may be delayed as long as seven years; merely reducing the burden may suffice.

Is it possible to predict which patients will benefit from thymectomy? Other controversies pale by comparison to the questions about thymectomy itself, or the surgical approach, but other differences of opinion should be noted. Originally, it seemed that young women were the best candidates for thymectomy, but this could have been an artefact of selection since young adult patients would be most likely to be selected for a major surgical procedure, and most young adult patients with myasthenia (and no thymoma) are women; some men and some older patients have improved in virtually every report. Short duration of symptoms has been deemed important, especially in recent years, ${ }^{29}{ }^{33}$ but in the single largest series, improvement rates were the same for patients with symptoms for more or less than five years. ${ }^{44}$ The histology of the thymus has been considered important, but some authors regarded presence of germinal centres as favourable $^{60}$; others considered lack of germinal centres favourable, ${ }^{33} 364661$ or found that thymic histology was not related to outcome. ${ }^{296264}$ As McQuillen and Leone ${ }^{48}$ pointed out, these discrepancies may not be surprising because it has not been proven that germinal centres are actually abnormally numerous in glands of patients with myasthenia. ${ }^{6566}$

There has been concern about doing thymectomies in pre-adolescent children ${ }^{67}$, but the rates of improvement seem no different from those in adults and no long-range harm has become evident, even when the operation was performed in children as young as two years. ${ }^{45}$ 68-74

It is probably fair to state that there are no reliable predictors of favourable outcome. The most common indication for thymectomy is disabling myasthenia, but "disabling" permits considerable room for subjective choice by the physician. As the operation becomes safer, and as more physicians become convinced of the value of the operation, more patients are selected for thymectomy and, increasingly, during the first year or two of symptoms.

Can "early" thymectomy prevent "progression" of myasthenia? Although it is difficult to find evidence in the literature, it has been stated that early thymectomy prevents "progression" of mild myasthenia to a severe state. ${ }^{33}$ Because of this view, the Mount Sinai group has attempted to identify which patients with solely ocular myasthenia are destined to have generalised disease. ${ }^{75}$ If a patient with solely ocular symptoms shows either a decremental response to repetitive stimulation of a limb nerve or abnormal sensitivity to curare to a local challenge of limb muscles with this drug, the disease is considered "generalised" and some of these patients have been subjected to thymectomy. Bever et al, ${ }^{76}$ however, found no correlation between the results of curare test or repetitive stimulation and subsequent-course of patients with ocular myasthenia.

Does steroid therapy enhance the results of thymectomy? It is probably true that, in most centres, steroid therapy is started only after thymectomy for most patients, at some time when physicians worry that improvement is not evident soon enough. This time depends upon the severity of symptoms; the more severe the disease, the sooner steroid therapy will be instituted. However, Johns and his associates ${ }^{77}$ have urged treatment with steroids before thymectomy because 
steroid-induced improvement may make the postoperative course less onerous. For other clinicians, this policy introduces new problems. The outcome of steroid therapy is itself uncertain in time and degree; if patients are chosen on grounds of disability, why operate on a patient in remission, steroid-induced or spontaneous? To avoid uncertainty about the appropriate timing of thymectomy after steroid therapy, why not do the thymectomy first and hope that this will avoid the risks of steroid therapy? These are some of the reasons why most centres do thymectomy first.

A new aspect of steroid therapy was introduced by Bolooki and Schwartzman ${ }^{78}$ who advocate administration of methylprednisone, given intravenously in divided doses just before, during and after the operation for a total of $1000 \mathrm{mg}$ in 24 hours. They believe that the regimen greatly reduced the morbidity of the trans-sternal approach; all 32 patients so treated left the intensive care unit within 24 hours. There have been no controlled studies of this approach, nor any reports from other centres.

Why should thymomas be excised? There is no debate about the advisability of surgical excision of thymoma in patients with myasthenia; it is done routinely. However, when a thymoma is present, thymectomy is less likely to be followed by improvement than in patients without thymoma. The indication for surgery of thymoma is therefore said to be the possibility that the tumour may ultimately invade neighbouring structures. In fact, symptoms are only rarely due to invasion of pericardium, lung, or superior vena cava $^{79}$ and the myasthenia sometimes does improve. Possible improvement of myasthenia is the "secret indication" in these patients, as in those without tumour.

One of the mysteries of thymectomy is how it exerts its beneficial effects. This is illustrated by some patients who do not have symptoms of myasthenia until some time (often years) after a thymoma has been removed. At first, it seemed that some thymic tissue was probably left behind in these cases, ${ }^{80}$ but Namba and Grob ${ }^{81}$ provided evidence that there had been apparently complete thymectomy in several patients with this kind of delayed myasthenia. Does that mean thymic cells had seeded other lymphoid organs before the tumour and thymic gland were removed? In contrast, however, myasthenia and tumour may both reappear after initial remission ${ }^{82}$; some patients experience remissions even if the thymoma is not removed ${ }^{83}$; and sometimes there is no autopsy evidence of thymic tissue even in fatal myasthenia. ${ }^{10} 84$ There is still much to be learned about the relation of the thymus to myasthenia. ${ }^{85}$

\section{STEROIDS}

Is steroid therapy effective in myasthenia gravis? Even to raise this question seems almost sacrilegious, because prednisone is now a staple of current therapy. It was not always so; there was a lag of almost 20 years from the first use of ACTH to some kind of general acceptance. But, as with other forms of myasthenia therapy, "acceptance" is not to be equated with rigorous proof of efficacy, safety, or clear indications for use. A brief review of steroid therapy provides a commentary on the sociology of academic neurology, especially in the United States.

ACTH first became available for therapeutic trials in 1950; its effects in the treatment of rheumatoid arthritis led to the award of a Nobel Prize and to use in other diseases of unknown cause. At that time, myasthenia was not regarded as an autoimmune disease. The first neurologists to be entrusted with limited supplies were Houston Merritt and Harold Wolff. Merritt, with Gilbert Glaser, used the drug in many different disorders, including one patient with severe myasthenia gravis who had "a partial remission" but died a few weeks later. ${ }^{86} 87$ Wolff, on the other hand, concentrated on myasthenia, reporting some improvement in ten of 15 cases; the improvement, however, was preceded by exacerbation of weakness and one patient died on therapy. ${ }^{88} 89$ Therefore two of the first 16 patients treated with ACTH died. Attention was directed to the possibly adverse effects of ACTH even though severe myasthenia was indeed grave in those days; the reported benefits were overshadowed

Negative views of the effects of corticosteroids were reinforced by two other early reports, one from the Mayo Clinic ${ }^{90}$ and the other from Johns Hopkins ${ }^{91}$; both papers were influential because the writers were such highly respected authorities on myasthenia. The Hopkins paper was especially powerful and the story was told in the title of the paper: a patient was being treated with cortisone for rheumatoid arthritis when symptoms of myasthenia first appeared. If a drug cannot prevent the first symptoms of a disease, how can it be effective in therapy?

As a result of these experiences, there were no reports of steroid therapy from any of the major myasthenia centres for more than a decade. There were still, however, occasional reports of benefit ${ }^{92} 98$ and this provided the background 
for a peculiar episode in the early $60 \mathrm{~s}$. At that time, several clinicians were concerned about the lack of controlled trials to evaluate thymectomy and they met to design a suitable protocol. The question of appropriate controls, however, seemed insurmountable; even then, the notion of sham operation was theoretically desirable but was deemed ethically impossible. Also, the cooperation of individualistic centres was difficult to achieve. To prepare for some kind of cooperative trial of thymectomy, therefore, the participants agreed to study the effects of ACTH on ocular myasthenia.

For several reasons, this seemed to be an ideal way to devise methods of cooperative investigation. Eye movements before and after therapy could be photographed and measured, objectively and quantitatively, without recourse to subjective evaluation and difficult-to-define words such as "improved". Evaluation could be completely "blind"; photographs were sent to another city and measurements were made without knowledge of therapy, whether it was placebo or ACTH, or even whether the photographs were taken before, during, or after therapy. Finally, because the patients had solely ocular symptoms and because the duration of therapy was limited, the patients were not being subject to any serious risk.

So the trial was initiated. Cooperation among the participating centres was excellent. The results were unequivocal. ACTH therapy, 580 units given in eight days, had no effect. ${ }^{94}$

The issue could have ended there. But the very next year, at an international conference on myasthenia, von Reis et $a l^{95}$ described and presented motion pictures to prove, dramatically, how beneficial ACTH therapy could be in patients with severe generalised myasthenia. Within a year, Grob and Namba ${ }^{96}$ and Osserman and Genkins ${ }^{97}$ confirmed these reports and steroid therapy was established throughout the world. The next logical step was taken when oral treatment with prednisone replaced injections of ACTH in 1971.98 The wave of enthusiasm sank the cooperative trial, which disappeared from the literature without leaving a ripple. How could it have been so wrong? Perhaps because generalised and ocular myasthenia are not the same. Perhaps the dosage or duration of therapy was inadequate, but similar dosages and duration were said to be successful in generalised myasthenia. Perhaps the controlled trial was not wrong, because a critical review of the literature of prednisone indicates persisting uncertainties despite uniform endorsement of this form of therapy.

To evaluate the effects of prednisone therapy, we have analysed the 15 reports (from 10 centres) since $1971 .^{99-112}$ Of these, only one attempted a controlled study; Howard et al ${ }^{107}$ found that seven of ten treated patients improved but so did three of ten receiving placebo, and the difference was not statistically significant. The number of patients was small, and the patients all had mild myasthenia (because, ethically, the investigators did not believe they could withhold standard therapy from patients with severe symptoms). Therefore, there has been no adequately controlled study, and no controlled study of any kind for patients with severe disease (who are most likely to be treated with prednisone).

Fischer and Schwartzman ${ }^{102}$ described uniformly beneficial results in eight patients with solely ocular symptoms. The other reports concerned 216 patients with generalised myasthenia, but, taking the most recent reports, only three of them described series of more than 20 patients each. ${ }^{101} 109110$ The results of each report, bar one, were fantastic.

Some reported improvement in every single patient treated ${ }^{98-101} 104108$ and the rate dropped only slightly in later reports from three of these centres, to $84 \%,{ }^{105} 89 \%{ }^{106}$ and $92 \% .^{110}$

The only dissent from these reports of almost universal improvement came from Kornfeld et $a l^{109}$ who found benefit before thymectomy in only $17 \%$ of patients with thymoma and only $30 \%$ of those without thymoma. After thymectomy, however, these authors found $100 \%$ improvement in patients with thymoma but still only $50 \%$ of patients without thymoma. Since negative therapeutic results are less likely to be reported the experience in some other centres may be in line with the results of Kornfeld et al, but that, of course, cannot be proven until the data are published.

There are other discrepancies in these published reports. Transient exacerbation of weakness was reported by some, 99101104107110 denied by others, ${ }^{98} 100102103$ and not mentioned by Kornfeld et al. ${ }^{109}$ Signs of improvement were noted as early as the first day or within one week ${ }^{100}{ }^{102}$; within two weeks, but later extended to one month ${ }^{106}$; one month ${ }^{103} ; 40$ days $^{104}$; or 50 days. ${ }^{110}$

It is important to know the upper limit of timeto-improvement because, if there is no improvement, the clinician must know when it is appropriate to discontinue therapy as a failure. This question was not specifically addressed in any of these reports but it would seem that two or three months should be adequate. Time-to- 
maximum-benefit is similarly important, also not specifically considered, but given as less than one month, ${ }^{101} 1068$ months, ${ }^{104} 15$ months ${ }^{100}$ and even 55 months. ${ }^{110}$

Almost all of these investigators first used a daily dosage of at least $50 \mathrm{mg}$ (or $100 \mathrm{mg}$ on alternate days). There is virtually no information about the longterm use of prednisone; how long full dosage should be given, when or to what levels dosage may be reduced; in how many patients drug-induced remission is permanent and prednisone therapy can be discontinued; or how often it must be continued because patients relapse when dosage is reduced. Sanders et $a^{110}$ routinely used prednisone before thymectomy so that the postoperative course will be more benign, but the data of Kornfeld et al ${ }^{109}$ suggest that this policy may not be appropriate. It is not clear whether prednisone is more or less beneficial in children than in adults, because it has been used in only a few children, ${ }^{102} 110$ and similar questions may be raised about the elderly. ${ }^{112}$

Is prednisone therapy safe? Do the benefits justify the risks? Some authors reported no complications ${ }^{99} 109$ or nothing more than the cosmetic effects of Cushing syndrome or glycosuria. ${ }^{102}{ }^{107} \mathrm{It}$ is not possible to ascertain the incidence of more serious complications that have included vertebral collapse $^{98103106110}$; congestive heart failure ${ }^{98}$; gastric haemorrhage ${ }^{106110}$; ruptured diverticulum $^{110}$; tracheal abscess ${ }^{106}$; psychosis ${ }^{104}$; cataracts $^{105106}$ aseptic necrosis of b one ${ }^{105} 110$; and sepsis. ${ }^{110}$

Two deaths were attributed to steroid therapy. ${ }^{110}$ No one has described the signed release used to explain these potential side effects in attempts to obtain informed consent for chronic prednisone therapy.

Does steroid therapy have pharmacological effects at the neuromuscular junction? The rationale for use of steroid therapy depends upon immunological theories of the disease, although it is not known precisely how steroids alter the pathological immune state. Several investigators have evaluated the possibility that steroids might repair the physiological abnormality of myasthenia ${ }^{113-117}$ but the balance of evidence suggests that this cannot be the basis for the beneficial effect. ${ }^{118 \cdot 119}$

How can we summarise the present state of prednisone therapy? It is now standard and customary, but has not been subject to controlled trial and the incidence of documented risk has not been ascertained. It is therefore uncertain whether it should be used at all in patients who are not seriously disabled, in children, or in the elderly. It is not clear whether it should be used before or after thymectomy. It is uncertain how long full dosage should be continued before deeming any trial a failure. It is not known how long full dosage should be continued when there is apparent benefit, or how often treatment can be terminated without adverse effect. The reports of almost universal benefit cannot be taken at face value because of a single published dissent and because, if the results were as good as described, there would be little interest in plasmapheresis or immunosuppressive drugs.

\section{IMMUNOSUPPRESSIVE DRUGS}

At the 1970 international meeting on myasthenia, I was asked to review experience with immunosuppressive drugs. ${ }^{120}$ There had been reports of immunosuppressive drug therapy in only 46 patients and 38 of them had improved, ${ }^{120}$ but 38 of these patients (including 32 who improved) had been reported from one centre by Mertens et al. ${ }^{121} \mathrm{By}$ means of a poll of centres in the US, we could obtain information about 14 cases treated with immunosuppressive drugs, but without detailed data; improvement was reported in four of these cases and the drug was discontinued in three. In sum, at that time, 60 patients were known to have been treated and 36 had improved.

A decade later, Hertel et $a l^{122}$ held my paper responsible for a chilling effect on the use of these drugs, but that view exaggerates any influence I might have (or anyone else, for that matter). What stopped research on the use of immunosuppressive drugs in the US was the litiginous nature of American society. At the 1970 meeting, I described the tragic case of a woman with life-threatening myasthenia who had an exaggerated bone marrow response to 6-mercaptopurine, became infected, suffered a myasthenic crisis, and died. That case resulted in a law-suit, euphemistically called "professional liability" here; the patient died in 1963 and legal action continued until the case was settled in 1973. The case was widely known among American investigators and probably did more to inhibit the use of these drugs than anything else; no physician wants to be accused of malpractice. For that reason, now, as in 1970, we have to look to European experience to evaluate immunosuppressive drug therapy.

Since 1971, there have been reports of only four series of patients who were treated with azathioprine without simultaneous prednisone therapy. Matell et $a^{123}$ found that $78 \%$ of 26 patients improved and three patients were in 
complete remission; the dosage was $2 \mathrm{mg} / \mathrm{kg}$ body weight. Improvement was not seen until after six to 12 weeks and the maximal effect appeared in six to 15 months. Because the "gradual effect makes it difficult to evaluate the effect properly", azathioprine was discontinued every year or two to determine whether there had been a spontaneous remission, but the results of this test were not stated. The drug had to be withdrawn because of agranulocytosis in only one patient. Sepsis and pneumonia affected two patients, one fatally.

Hertel et al $^{122}$ used 150-200 $\mathrm{mg}$ azathioprine without steroids, to treat 64 patients. Thirtythree patients were given the drug after thymectomy, so that the prolonged improvement included the effects of both treatments but they implied that azathioprine hastened or enhanced the results of thymectomy (although specific data were not given); four years after thymectomy, they were still improving. Very severe myasthenia was treated with both corticosteroids and azathioprine in 15 cases and all but one improved. Only one patient had severe bone marrow depression that lasted for several months, and therapy did not have to be discontinued in any patient because of hepatic or gastrointestinal toxicity. One patient died of sepsis and another had orchitis.

Reuther et al ${ }^{124}$ studied AChR antibody responses in nine of the patients mentioned by Hertel et al ${ }^{122}$; three had thymectomies. Titres declined to about $70 \%$ of the initial values by three years and to $40 \%$ after five years. Although all patients improved and seven were in remission, abnormal antibody titres persisted in all of them.

Newsom-Davis $e t a^{125}$ gave azathioprine in a daily dosage of $2.5 \mathrm{mg} / \mathrm{kg}$, to six patients; five had thymectomy and five were receiving prednisone. They were compared to seven patients who received the drug (concomitant with prednisone in four and who were also treated by plasma exchange. Six of the 13 patients improved in the observation period of four to 12 weeks, and all patients showed a decline in antibody titres, but there were no significant differences between the two groups. No serious side-effects were reported.

There have been reports of treatment with other immunosuppressive drugs that are not generally available ${ }^{126}$ or with antithymocyte globulin ${ }^{127} 128$ but the numbers of patients were too small to evaluate critically.

Since 1970, there has been one major change; there is now a clear rationale for the use of immunosuppressive drugs. Because of a single law-suit in the United States, there has been little experience with these drugs in this country. As in 1970, the reports of azathioprine seem promising. As in 1970, there has been no controlled trial of effects that only appear gradually. Three deaths have been attributed to azathioprine or its metabolite, mercaptopurine ${ }^{120} 123129$ but it is not known whether azathioprine is more or less hazardous than prednisone, whether it should be given alone or in combination with prednisone, or whether it improves the results of thymectomy alone. Even the proper dosage is uncertain. That is, it is not clear whether an arbitrary dosage of $2.5 \mathrm{mg} / \mathrm{kg}$ is appropriate for all patients or whether the dosage should be increased to cause mild leucopenia as evidence of biological effect (but, presumably, with increased risk). The situation is not tidy.

\section{PLASMAPHERESIS}

That myasthenia might be an autoimmune disonder was first suggested by Smithers in 1959130; the theory captured attention after the seminal paper of Simpson ${ }^{2}$ and the demonstration of antibodies to muscle striations by Strauss et $\mathrm{al}^{\mathbf{4}}$ in 1960. By the end of the decade, however, there was much uncertainty because the striation-binding antibodies were lacking in most cases, could not explain the disorder of neuromuscular transmission, and could not be demonstrated consistently in neonatal myasthenia. Attention was therefore being directed to alterations of cell-mediated immunity, when the first attempts were made in 1969 to remove immunopathogens from the myasthenic patient. Since cell-mediated mechanisms were suspected, it was therefore surprising that the benefits of thoracic duct drainage seemed to be due to something in plasma rather than the lymphocytes. ${ }^{131} 132$ In retrospect, another observation of that time could have been due to removal of plasma, for an infant with neonatal myasthenia improved promptly after an exchange transfusion for $\mathbf{R} h$ incompatibility. ${ }^{133}$

These early observations made more sense a few years later, after the elucidation of experimental autoimmune myasthenia and the demonstration of antibodies to AChR in human patients. The technology of human blood separation had also advanced and it was therefore logical to attempt to remove the pathogenic antibodies by plasma exchange, or plasmapheresis. The first report, by Pinching et al, ${ }^{134}$ had a major impact; there is now published information about the use of this technique in 94 patients ${ }^{125}$ 135-142 and 11 patients have been studied at the Colum- 
bia-Presbyterian Medical Center. ${ }^{143}$

As usual, the first reports were most enthusiastic, reporting universal improvement in patients who received prednisone and either azathioprine or cyclophosphamide in addition to plasma exchange. ${ }^{134} 135$ But there have been some disappointments. Howard et al ${ }^{137}$ reported improvement in all eight patients who received prednisone as well but "not adequately" in five. Behan et $a l^{\mathbf{1 4 2}}$ reported six failures in 21 patients who were receiving both prednisone and azathioprine at the time of plasma exchange.

With a procedure so new, it is not appropriate to speak of "controversy" but there are certainly unanswered questions, and we shall pose some of these.

What are the risks of plasma exchange? Apparently not many. The worst on record were one fatality attributed to azathioprine ${ }^{\mathbf{1 4 2}}$ and one case of subacute bacterial endocarditis ${ }^{134}$ in which a Scribner shunt had been used; venous catheterisation usually provides adequate access. Susceptibility to infection may increase and influenza-like syndromes may be more frequent after plasma exchange. ${ }^{137147}$ Mild transient worsening of myasthenia was reported only by Lisak $e t a^{138}$ and there is no evidence of adverse effect from loss of pyridostigmine or prednisone in the discarded plasma.

How expensive is plasma exchange? In New York, it costs $\$ 350$ for the disposable tubing used in each exchange. To this must be added the cost of purchasing and maintaining the cell separator, professional costs for physicians and nurses who perform the exchange, and hospital costs. The total could be at least $\$ 800$ for each treatment. The procedure could be performed on some ambulatory patients, but laboratory tests are necessary so hospital costs cannot be completely eliminated.

Can we predict, on clinical grounds, which patients are most likely to improve? The answer seems to be "No". Improvement has been reported in patients with mild or severe symptoms, in the young and the elderly (although not yet in many children); before or after thymectomy; with or without prior or concomitant administration of prednisone or immunosuppressive drugs; and with or without thymoma. Congenital myasthenia may or may not be an exception; the procedure failed in two children ${ }^{141}$ and one adult with lifelong symptoms ${ }^{143}$ but this need not imply universal failure in these cases.

Can we predict improvement on the basis of antibody titres? Because plasma exchange was introduced to decrease the titre of circulating antibodies to AChR, it would seem logical to reserve the procedure for patients with high titres of these antibodies, but there are several theoretical reasons why this might not be so: (1) Antibodies are not detected in all patients with myasthenia gravis; depending upon the laboratory and the method, abnormal titres were present in as many as $85 \%^{144}$ of patients or as few as $50 \% .{ }^{145}$ In either case, a substantial number lack the antibodies. In six patients with congenital myasthenia antibodies were lacking. ${ }^{147}$ (2) When antibodies are present, there is no strict relation between the titre and severity of symptoms. (3) If antibodies to AChR cause the symptoms of myasthenia, these observations suggest that the amount of antibody bound to neuromuscular junctions may not be proportionate to the titre of circulating antibody. (4) Alternatively, the beneficial effects of plasma exchange could be due to removal of a substance other than antibody to AChR. For instance, plasma content of thymic hormone decreases after thymectomy ${ }^{147}$ and is probably also removed by plasma exchange, or there may be changes in immune complexes $^{148}$ or other plasma constituents that have not yet been identified.

However, efficacy of a treatment can force us to revise theory, and it is therefore necessary to evaluate the data. In general terms, and in most patients, AChR antibody titres have declined as patients improved after plasmapheresis, ${ }^{136141}$ and two patients with congenital myasthenia who lacked antibody both failed to improve. ${ }^{141}$ But there have been some notable exceptions. Newsom-Davis et $a l^{141}$ reported a significant drop in antibody titre in one clinical failure of plasma exchange. Dau et al ${ }^{136}$ found comparable changes in antibody titres of patients who showed little or much improvement. Howard et al ${ }^{137}$ reported improvement in two patients who lacked detectable antibody, and we have seen one such patient. ${ }^{143}$ It is therefore necessary to gather more data about the relation of antibody responses to clinical improvement after plasma exchange.

Is it necessary to administer prednisone or immunosuppressive drugs for therapeutic benefit of plasma exchange? This question cannot be answered from available data and it is of major practical importance because of the risks of the drugs. The question cannot be answered because almost all of the published cases were receiving steroids or immunosuppressive drugs. Both Newsom-Davis $e t a l^{141}$ and Dau et al ${ }^{136}$ were impressed by the theory (that drugs are necessary to delay reappearance of the pathogenic 
antibodies) and by a few failures in patients who did not respond without these adjuvants. Additionally, the two groups noted "rebound" in four patients who were not receiving azathioprine; that is, antibody titres after plasma exchange gradually increased to levels higher than the original as symptoms returned. However, one of the patients of Dau et $a l^{136}$ was apparently better clinically at the time of antibody "rebound" and symptoms returned only later. Lisak and Schotland ${ }^{138}$ reported that seven of nine patients "have done well without additional treatment".

Therefore, the role of prednisone and immunosuppressive drugs is not yet defined.

Does plasmapheresis add to the benefit of chronic azathioprine therapy alone? While documenting the acute benefits of plasma exchange, NewsomDavis $e t a l^{141}$ found that the long-term effects of azathioprine alone were not improved by intermittent plasma exchange.

What are the indications for plasmapheresis? Considering the costs and still unknown risks, almost all investigators have reserved plasmapheresis for patients who are seriously disabled, usually after other forms of treatment have failed. However, the procedure could be used before other treatments in some circumstances. For instance, it may be effective in the treatment of myasthenic crisis (defined as the need for assisted respiration) if patients do not recover independent ventilation in a few days. Or it could be used to improve the clinical condition of a patient who is being prepared for thymectomy, hoping to make the postoperative course less arduous. For patients who have failed to respond to thymectomy, prednisone or immunosuppressive drugs, plasma exchange has already been of value in providing sustained improvement for weeks or months. For some patients, intermittent plasma exchange may be a suitable alternative to the risks of chronic therapy with steroids or immunosuppressive drugs.

Are controlled trials necessary to evaluate the therapeutic effects of plasmapheresis? If a patient has stable and disabling symptoms of myasthenia for several months, and if these symptoms improve obiectively within a few days of a series of plasma exchanges, controlled trials seem superfluous. Indeed, it would probably be ethically impossible to design a controlled trial that would include sham plasmapheresis. In this regard plasmapheresis differs from the problems generated by interventions that may take weeks, months or years to have an effect, as in the use of thymectomy, steroids, or immunosuppressive drugs. Another aspect of plasma exchange, however, poses a different problem. The procedure is already being used to treat patients in respiratory crisis, and this may be one of the most important indications. However, it will be difficult to ascertain that treatment with plasmapheresis actually shortens the duration of these episodes of crisis. Because crisis seems to be becoming less frequent, it is not likely that controlled trials can be done in any one institution and we will probably have to compare the duration of crisis before and after the time plasma exchange was introduced.

\section{Conclusion}

This essay mav seem nihilistic to some; it is not meant to be. In our centre, we tend to recommend thymectomy more and more. If the patient does not then improve within a reasonable period of time (and "reasonable" permits considerable latitude, depending upon the severity of symptoms and the patient's desires as well as the judgement of one or more physicians), then we use prednisone. If there is still no improvement after some uncertain period of time, or if there have been serious side-effects, we then use azathioprine. We have begun to use plasmapheresis, but everyone recognises the uncertainty of the proper application of this technique. Sometimes, if a patient has a crisis before thymectomy, steroids or immunosuppressive drugs are used before the operation.

In practice, therefore, we behave like most other physicians who care for patients with myasthenia. Therapeutic nihilism can go just so far. But I am repeatedly concerned about what seems to be uncritical acceptance of new therapies. Each of the major approaches to alter the course of the disease (thymectomy, prednisone, immunosuppressive drugs) has been endorsed enthusiastically without controlled trials. Yet if any were the panacea that original reports claimed, would plasmapheresis be greeted so warmly?

Indeed, where do all the subjects for plasmapheresis come from, if thymectomy, prednisone and azathioprine are uniformly beneficial?

These techniques are now all encrusted as "accepted practice" and they bear the sacred imprimatur of "the literature". It becomes increasingly difficult to justify, on ethical grounds, a controlled trial. Yet for treatments that require months or years to bestow benefit, and for a 
Table Thirty unanswered questions about the therapy of myasthenia gravis

1 How should we determine the optimal dose of a cholinergic drug?

2 Is one cholinergic drug more effective than another?

3 Does cholinergic crisis occur in patients taking, by mouth, conventional reversible inhibitors of anticholinesterase?

4 Is the edrophonium test of value in determining optimal dosage or in defining cholinergic crisis?

5 In the management of myasthenic crisis, should cholinergic drug therapy be discontinued? If so, when should it be re-instituted?

6 Would management be improved by monitoring blood levels of cholinergic drugs?

7 Is thymectomy of proven value in the treatment of myasthenia?

8 If so, how does it work?

9 Which patients are most likely to improve after thymectomy?

10 Does thymectomy prevent progression of myasthenia to a more serious disease? Should every patient with generalised myasthenia have thymectomy? As soon as the diagnosis is made?

11 Should prednisone be given routinely before thymectomy?

12 Should thymectomy be done before adolescence or after some arbitrary older age (for example after 65 years)?

13 Is cervical thymectomy as effective as trans-sternal thymectomy?

14 Is prednisone of proven value in treating myasthenia?

15 Is one corticosteroid preferable to another?

16 What dosage should be used? For how long?

17 If there is no improvement, how long should steroid therapy be continued before deeming the trial a failure?

18 Are steroids safer or more hazardous than azathioprine?

19 How should properly informed consent be obtained before a patient embarks upon prolonged steroid therapy?

20 Are immunosuppressive drugs of proven value in treating myasthenia?

21 Is any one immunosuppressive drug preferable to another?

22 Should immunosuppressive drugs be given before, after, or with steroid drugs?

23 What dosage should be used? Should it be arbitrary, according to body weight, or should mild leucopenia be induced?

24 Which patients will benefit most from plasmapheresis?

25 Does plasmapheresis shorten the duration of myasthenic crisis?

26 Is plasmapheresis of benefit in preparing patients for thymectomy?

27 Is there a role for plasmapheresis in long-term management of myasthenia?

28 Is plasmapheresis beneficial because it removes antibody to AChR or because it removes something else?

29 Can plasmapheresis be beneficial if antibodies to $A C h R$ are not detected in an individual patient?

30 Is it necessary to administer prednisone or azathioprine for either acute or long-lasting benefit of plasmapheresis?

disease whose "natural" history is not now known, controls would certainly seem desirable. If controlled studies had been done early, we would not be left with so many unanswered questions (table). Clinicians must decide whethęr to use thymectomy, plasmapheresis, steroids or immunosuppressive drugs, in what sequence or combinations, and when to deem lack of improvement a sign for a different therapeutic approach. Even proponents of specific regimens must admit that the guidelines are not clear.

That is the problem, in general terms. It may all sort out in time. In the meantime, each centre will proceed according to the preferences of local physicians. Certainly, myasthenia is not the grave disease it was only 20 years ago; we must be doing something right.
The author's views have been tempered by association with other clinical investigators, including Paul FA Hoefer, Henry Aranow Jr, Audrey S Penn, Robert E Lovelace, MR Olarte, and Richard Schoenfeldt. Alfred Jaretzki III has provided thoughful leadership in questions about thymectomy. George Zito gave generous assistance in the analysis of data about steroid therapy. To all of them I am indebted, but none of them is responsible for any errors, intemperate comments, or apparent lapses of judgement in this essay.

\section{References}

1 Simpson JA. An evaluation of thymectomy in myasthenia gravis. Brain 1958; 81:112-44.

2 Simpson J. Myasthenia gravis: a new hypothesis. Scot Med J 1960; 5:419-36.

3 Simpson JA. A morphological explanation of the transmission defect in myasthenia gravis. $A n n$ NY Acad Sci 1971; 183:241-7.

4 Strauss AJL, Seegal BC, Hsu KC, Burkholder PM, Nastuk WL, Osserman KE. Immunofluorescence demonstration of a muscle-binding complement-fixing serum globulin fraction in myasthenia gravis. Proc Soc Exp Biol Med 1960; 105:184-91.

5 Engel AG, Santa T. Histometric analysis of the ultrastructure of the neuromuscular junction in myasthenia gravis and in the myasthenic syndrome. Ann NY Acad Sci 1971; 183:46-63.

6 Fineberg HV, Hiatt HH. Evaluation of medical practices. The case for technology assessment. New Engl J Med 1979; 301:1086-91.

7 Fletcher RH, Fletcher SW. Clinical research in general medical journals. A 50 year perspective. New Engl J Med 1979; 301:180-3.

8 Osserman KE. Myasthenia Gravis. New York: Grune and Stratton, 1958: 155-8, 169.

9 Rowland LP, Korengold MC, Jaffe IA, Berg L, Shy GM. Prostigmine-induced muscle weakness in myasthenia gravis patients. Neurology (Minneap) 1955; 5:89-99.

10 Rowland LP, Hoefer PRA, Aranow HJR, Merritt HH. Fatalities in myasthenia gravis. A review of 39 cases with 26 autopsies. Neurology (Minneap) 1956; 6:307-26.

11 Cohan SL, Pohlmann JLW, Mikszewski J, O'Doherty DS. The pharmacokinetics of pyridostigmine. Neurology (Minneap) 1976; 26:536-9.

12 Kornfeld P, Mittag TN, Genkins G, Horowitz S, Papatestas AE. Studies in myasthenia gravis: pyridostigmine- $\mathrm{C}^{14}$ metabolism after thymectomy. Neurology (Minneap) 1975; 25:998-9.

13 Chan K, Calvey TN. Renal clearance of pyridostigmine in patients with myasthenia gravis. Eur Neurol 1977; 16:69-72.

14 Cohan SL, Dretchen KL, Neal A. Malabsorption 
of pyridostigmine in patients with myasthenia gravis. Neurology (Minneap) 1977; 27:299-301.

15 Calvey TN, Chan K. Plasma pyridostigmine level; in patients with myasthenia gravis. Clin Pharm. Therap 1977; 21:187-93.

16 White MC, De Silva P, Havard CWH. Plasma pyridostigmine levels in myasthenia gravis. Neurology (Minneap), in press.

17 Engel AG, Lambert EH, Santa T. Study of longterm anticholinesterase therapy. Neurolog; (Minneap) 1973; 23:1273-81.

18 Hudson CS, Rash JE, Tiedt TN, Albuquerque EK. Neostigmine-induced alterations at the mammalian neuromuscular junction. $J$ Pharmacol Exp Ther 1978; 205:340-56.

19 Schwartz MS, Sargeant MK, Swash M. Neostigmine-induced end-plate proliferation in the rat. A study using supra-vital methylene blue. Neurology (Minneap) 1977; 27:289-93.

20 Ward MD, Forbes MS, Johns TR. Neostigmine methylsulfate. Does it have a chronic effect as well as a transient one? Arch Neurol 1978; 32: 808-14.

21 Mayer RF, Albuquerque EX, Rash JE, Hudson CS. Neuromuscular junction and myasthenic crisis. Trans Am Neur Assoc 1977; 102:1-4.

22 Blalock A, Mason MF, Morgan HJ, Riven SS. Myasthenia gravis and tumors of the thymic region: report of a case in which tumor was removed. Ann Surg 1939; 110:554-61.

23 Schwab RS, Viets HR. Myasthenia gravis. Res Proc Assoc Res Nerv Ment Dis 1960; 38:624-37.

24 Keynes G. Investigations into thymic disease and tumor formation. Brit J Surg 1955; 42:449-62.

25 Rowland LP. Myasthenia gravis. In: Mark LC, Papper EM, eds. Advances in Anesthesiology: Muscle Relaxants. Boston: Harper and Row, 1967: 85-113.

26 Jaretzki A. Symposium on therapeutic controversies: Myasthenia gravis. Cervical thymectomy (con). Trans Am Neurol Assoc 1978; 103:288-91.

27 Buckingham JM, Howard FM Jr, Bernatz PE et al. The value of thymectomy in myasthenia gravis. A computer-assisted matched study. Ann Surg 1976; 184:453-8.

28 Cohn HE, Solit RW, Schatz NJ, Schlezinger N. Surgical treatment in myasthenia gravis. $J$ Thorac Cardiovasc Surg 1974; 68:876-85.

29 Emerik KB, Strugalska MH. Evaluation of results of thymectomy in myasthenia gravis. J Neurol 1976; 211:155-68.

30 Farnsworth A, Pries W, Mendelsohn H. Thymectomy for myasthenia gravis. A ustralia NZ J Surg 1976; 46:170-3.

31 Faulkner SL, Ehyai A, Fisher RD, Fenichel GM, Bender HW Jr. Contemporary management of myasthenia gravis; the clinical role of thymectomy. Ann Thorac Surg 1977; 23:348-52.

32 Fraser K, Simpson JA, Crawford J. The place of surgery in the treatment of myasthenia gravis. $\mathrm{Br}$ J Surg 1978; 65:301-4.
33 Genkins G, Papatestas AE, Horowitz SH, Kornfeld P. Studies in myasthenia gravis. Early thymectomy. Amer J Med 1975; 58:517-24.

34 Gschnitzer F. Thymectomy in myasthenia gravis. Z Ekr Atmungsorgane 1975; 142:284-9.

35 Keesey J. Indications for thymectomy in myasthenia gravis. In: Dau PC, ed. Plasmapheresis an! the Immunobiology of Myasthenia Gravis. Boston: Houghton Mifflin, 1979: 124-36.

36 Klingen G, Johansson L, Westerholm CJ, Sundstrom C. Transcervical thymectomy with the aid of mediastinoscopy for myasthenia gravis: eight years' experience. Ann Thorac Surg 1977; 23:342-7.

37 Le Brigand H, Levasseur P, Merlier M, RojasMiranda A, Gaud C, Noviant Y. Cent thymectomies chez des myastheniques. Rev Neurol 1972; 126:267-74.

38 Mattila S, Pirskanen R. Thymectomy for myasthenia gravis. In: Dau PC, ed. Plasmapheresis and the Immunobiology of Myasthenia Gravis. Boston: Houghton Mifflin, 1979: 137-43.

39 Mattila S, Pirskanen R, Heinonen J. Thymectomy for myasthenia gravis. Scand J Thorac Cardiovasc Surg 1976; 10:183-8.

40 Mulder DG, Herrmann C, Buckberg GD. Effect of thymectomy in patients with myasthenia gravis. Am J Surg 1974; 128:202-6.

41 Papatestas AE, Alpert LI, Osserman KE, Osserman RS, Kark AF. Studies in myasthenia gravis. Effects of thymectomy. Results on 185 patients with non-thymomatous and thymomatous myasthenia gravis. Am J Med 1971; 50:465-74.

42 Patten BM. Myasthenia gravis. In: Tyler HR, Dawson DM, eds. Current Neurology. Boston: Houghton Mifflin, 1978: 20-49.

43 Perlo VP. Symposium on therapeutic controversies: Myasthenia gravis. Thymectomy (pro). Trans Am Neur Assoc 1978; 103:282-3.

44 Perlo VP, Poskanzer DC, Schwab RS, Viets HR, Osserman KE, Genkins G. Myasthenia gravis: evaluation of treatment in 1355 patients. Neurology (Minneap) 1966; 16:431-9.

45 Ryniewicz B, Badurska B. Follow-up study of mvasthenic children after thymectomy. $J$ Neurol 1977; 217:133-8.

46 Takahashi M, Kang J, Takeuchi $\mathrm{H}$ et al. Evaluation of the effect of thymectomy in myasthenia gravis. Med J Osaka Univ 1978; 29:281-6.

47 McQuillen MP. Symposium on therapeutic controversies: Myasthenia gravis. Thymectomy (con). Trans Am Neur Assoc 1978; 103:283-6.

48 McQuillen MP, Leone MG. A treatment carol: thymectomy revisited. Neurology (Minneap) 1977; 27:1103-6.

49 Grob D. Course and management of myasthenia gravis. JAMA 1953; 153:529-32.

50 Pamboukis G, Anastasopoulos G, Prapopoulos G, Ruckbildung einer Myasthenia gravis nach chirurgischer Entfernung einer Echinokokkuszyste der Lunge. Wien Zschr Nervenheilk 
1955; 12:216-20.

51 Simpson JA. Myasthenia gravis. In: Walton JN, Canal N, Scarlato G, eds. Muscle Diseases. Amsterdam: Excerpta Medica, 1969: 14-22.

52 Genkins G, Papatestas AE, Kornfeld P, Horowitz SH. Studies in myasthenia gravis: staging and gamma globulin. In: Dau PC, ed. Plasmapheresis and the Immunobiology of Myasthenia Gravis. Boston: Houghton Mifflin, 1979: 144-50.

53 Papatestas AE, Genkins G, Kornfeld P, Horowitz S, Kark AE. Transcervical thymectomy in myasthenia gravis. Surg Gyn Obstet 1975; 140: $535-40$.

54 Papatestas AE, Genkins G. Symposium on therapeutic controversies: Myasthenia gravis. Cervical thymectomy (pro). Trans Am Neur Assoc 1978; 103:286-8.

55 Jaretzki A III, Bethea M, Wolff $\mathrm{M}$ et al. A rational approach to total thymectomy in the treatment of myasthenia gravis. Ann Thorac Surg 1977; 24:120-30.

56 Masaoka A, Nagoka Y, Kotake Y. Distribution of thymic tissue in the anterior mediastinum. $J$ Thorac Cardiovasc Surg 1975; 70:747-55.

57 Mink JH, Bein ME, Sukov R et al. Computed tomography of the anterior mediastinum in patients with myasthenia gravis and suspected thymoma. Am J Roentgenol 1978; 130:239-46.

58 Stump WJ, Adornato BT, Engel WK, McIntosh CL, Castleman BJ. Thymectomy in myasthenia gravis. Neurology (Minneap) 1978; 28:372-3.

59 Joseph BS, Johns TR. Recurrence of nonneoplastic thymus after thymectomy for myasthenia gravis. Neurology (Minneap) 1973; 23:109-19.

60 Sambrook MA, Reid H, Mohr PD, Boddie HG. Myasthenia gravis: clinical and histological features in relation to thymectomy. J Neurol Neurosurg Psychiatry 1976; 39:38-43.

61 Alpert IL, Papatestas A, Kark A, Osserman RS, Osserman K. A histological reappraisal of the thymus in myasthenia gravis. Arch Pathol 1971; 91:55-61.

62 Vetters JM, Simpson JA. Comparison of thymic histology with response to thymectomy in myasthenia gravis. J Neurol Neurosurg Psychiatry 1974; 337:1139-45.

63 Leong ASY, Vignaendra V, Ghee LT. A reappraisal of the significance of thymic germinal centers in myasthenia gravis. Eur Neurol 1976; 14:53-9.

64 Oosterhuis HJGH. The relationship between the histopathology of the thymus gland and the effect of thymectomy in myasthenia gravis. Rec $A d v$ Myology 1974; 360:517-21.

65 Middleton G. The incidence of follicular structures in the human thymus at autopsy. Aust $J$ Exp Biol Med Sci 1967; 45:189-99.

66 Levine GD. Pathology of the thymus in myasthenia gravis; current concepts. In: Dau PC, ed. Plasmapheresis and the Immunobiology of
Myasthenia Gravis. Boston: Houghton Mifflin, 1979: 113-23.

67 Mendell JR, Warmolts JR, Bass JC. Caution urged in childhood thymectomy for myasthenia gravis. Neurology (Minneap) 1977; 27:1182.

68 Fonkalsrud EW, Herrmann C Jr, Mulder DG. Thymectomy for myasthenia gravis in children. J Pediat Surg 1970; 5:157-65.

69 Fukuyama Y, Suzuki M, Segawa M. Studies on myasthenia gravis in childhood. Paed Univers Tokyo 1970; 18:57-68.

70 Hansson O, Johansson L, Stalberg E, Westerholm CJ. Thymectomy in juvenile myasthenia gravis. Neuropadiatrie 1972; 3:429-36.

71 Millichap JG, Dodge PR. Diagnosis and treatment of myasthenia gravis in infancy, childhood and adolescence. A study of 51 patients. Neurology (Minneap) 1960; 10:1007-14.

72 Sarnat HB, McGarry JD, Lewis JE Jr. Effective treatment of infantile myasthenia gravis by combined prednisone and thymectomy. Neurology (Minneap) 1977; 27:550-3.

73 Seybold ME, Howard FM, Duane DD, Payne WS, Harrison EG Jr. Thymectomy in juvenile myasthenia gravis. Arch Neurol 1971; 25:385-92.

74 Swaiman KF, Varco RL. Thymectomy: in fulminating myasthenia gravis of childhood. Minn Med 1972; 55:809-10.

75 Horowitz SH, Genkins G, Kornfeld P, Papatestas AE. Regional curare test in evaluation of ocular myasthenia. Arch Neurol 1975; 32:84-8.

76 Bever C, Aquino A, Penn AS, Rowland LP. Prognosis of ocular myasthenia gravis. Neurology (Minneap) 1980; 30:387-8.

77 Johns TR. Symposium on therapeutic controversies: Myasthenia gravis. Steroids and immunosuppressive drugs (pro). Trans Am Neur Assoc 1978; 103:278-80.

78 Bolooki H, Schwartzman RJ. Role of steroids in management of patients with myasthenia gravis undergoing thymectomy. J Thorac Cardiovasc Surg 1978; 75:754-7.

79 Goldman AJ, Herrmann C Jr, Keesey JC, Mulder DG, Brown WJ. Myasthenia gravis and invasive thymoma: a 20 year experience. Neurology (Minneap) 1975; 25:1021-5.

80 Rowland LP, Aranow H Jr, Hoefer PFA. Myasthenia gravis appearing after the removal of thymoma. Neurology (Minneap) 1957; 7: 584-8.

81 Namba T, Brunner NG, Grob D. Myasthenia gravis in patients with thymoma, with particular reference to onset after thymectomy. Medicine 1979; 57:411-33.

82 Lava NS, Rodichok L, Martinez LB. Recurrence of thymoma and myasthenia gravis after 19 years. Neurology (Minneap) 1976; 26:696.

83 Masaoka A, Monden Y, Seike Y. Spontaneous remission of myasthenia gravis in patients with thymoma. Neurology (Minneap) 1978; 28:495-6.

84 Perlo VP, Arnason BGW, Castleman B. The 
thymus gland in elderly patients with myasthenia gravis. Neurology (Minneap) 1975; 25:294-5.

85 Drachman DB. Myasthenia gravis. $N$ Engl J Med 1978; 298:136-42; 186-93.

86 Glaser GH, Merritt HH. Effects of corticotropin (ACTH) and cortisone on disorders of the nervous system. JAMA 1952; 148:898-904.

87 Merritt HH. Corticotropin and cortisone in diseases of the nervous system. Yale J Biol Med 1952; 24:466-73.

88 Torda C, Wolff HG. Effects of adrenocorticotrophic hormone on neuromuscular function in patients with myasthenia gravis. J Clin Invest 1949; 28:1228-935.

89 Torda C, Wolff HG. Effects of administration of the adrenocorticotrophic hormone on patients with myasthenia gravis. Arch Neurol Psychiat 1951; 66:163-70.

90 Millikan $\mathrm{CH}$, Eaton LH. Clinical evaluation of ACTH and cortisone in myasthenia gravis. Neurology (Minneap) 1951; 1:145-52.

91 Grob D, Harvey AM. Effect of adrenocorticotrophic hormone (ACTH) and cortisone administration in patients with myasthenia gravis and report of onset of myasthenia gravis during prolonged cortisone administration. Bull Johns Hopkins Hosp 1952; 91:124-36.

92 Schlezinger NS. Present status of therapy in myasthenia gravis. JAMA 1952; 148:508-13.

93 Freydberg CD. The place of corticotropin in the treatment of myasthenia gravis. Ann Int Med 1960; 52:108-18.

94 Mount FW. Corticotropin in treatment of ocular myasthenia. Arch Neurol 1964; 11:114-24.

95 Von Reis G, Liljestrand A, Matell G. Treatment of severe myasthenia gravis with large doses of adrenocorticotrophic hormone. Ann NY Acad Sci 1966; 135:409-16.

96 Grob D, Namba T. Corticotropin in generalised myasthenia gravis. JAMA 1966; 198:703-6.

97 Osserman KE, Genkins G. Studies in myasthenia gravis: short-term massive corticotropin therapy. JAMA 1966; 198:699-702.

98 Kjaer M. Myasthenia gravis and myasthenic syndromes treated with prednisone. Acta Neurol Scand 1971; 47:464-74.

99 Jenkins RB. Treatment of myasthenia gravis with prednisone. Lancet 1972 ; 1:765-7.

100 Warmolts JR, Engel WK. Benefit from alternate-day prednisone in myasthenia gravis. $N$ Engl J Med 1972; 286:17-20.

101 Brunner NB, Namba T, Grob D. Corticosteroids in management of severe generalised myasthenia gravis. Neurology (Minneap) 1972; 22:603-10.

102 Fischer KC, Schwartzman RJ. Oral corticosteroids in the treatment of ocular myasthenia gravis. Neurology $1974 ; 24: 795-8$.

103 Seybold ME, Drachman DB. Gradually increasing doses of prednisone in myasthenia gravis: reducing the hazards of treatment. $N$ Engl J Med 1974; 290:81-4.
104 Pinelli P, Tonali P, Scopetta C. Long-term treatment of myasthenia gravis with alternateday prednisone. Europ Neurol 1974; 12:129-41.

105 Engel WK, Festoff BW. Myasthenia gravis. Ann Int Med 1974; 81:225-46.

106 Brunner NG, Berger CL, Namba T, Grob D. Corticotropin and corticosteroids in generalised myasthenia gravis; comparative studies and role in management. Ann NY Acad Sci 1976; 274: 577-95.

107 Howard FM, Duane DD, Lambert EH. Alternate-day prednisone; preliminary report of a double-blind controlled study. Ann NY Acad Sci 1976; 274:596-607.

108 Johns TR. Treatment of myasthenia gravis: Long-term administration of corticosteroids with remarks on thymectomy. In: Griggs RC, Moxley RT III, eds. Treatment of Neuromuscular Diseases. New York: Raven Press, 1977: 99-122.

109 Kornfeld P, Genkins G, Papatestas AE, Horowitz SH. Steroid therapy in myasthenia gravis associated with thymoma. Mt Sinai $\mathrm{J} \mathrm{Mel}$ 1978; 45:106-15.

110 Sanders DB, Howard JF Jr, Johns TR, Campa JF. High-dose daily prednisone in the treatment of myasthenia gravis. In: Dau PC, ed. Plasmapheresis and the Immunobiology of Myasthenia Gravis. Boston: Houghton Mifflin, 1979: 289306.

111 Howard FM. Symposium on therapeutic controversies: Myasthenia gravis. Steroids and immunosuppressive drugs (caution). Trans $\mathrm{Am}$ Neurol Assoc 1978; 103:281.

112 Howard FM Jr. Myasthenia gravis with onset after 65 years of age; a preliminary report. In: Dau PC, ed. Plasmapheresis and the Immunobiology of Myasthenia Gravis. Boston: Houghton Mifflin, 1979: 281-8.

113 Arts WF, Oosterhuis HF. Effect of prednisone on neuromuscular blocking in mice in vivo. Neurology (Minneap) 1975; 25:1088-90.

114 Leeuwin RS, Wolters ECMJ. Effect of corticosteroids on sciatic nerve-tibilis anterior muscle of rats treated with hemicholinium-3. An experimental approach to a possible mechanism of action of corticosteroids in myasthenia gravis. Neurology (Minneap) 1977; 27:171-7.

115 Patten BM, Oliver KL, Engel WK. Adverse interaction between steroid hormones and anticholinesterase drugs. Neurology (Minneap) 1974; 24:442-9.

116 Strand FL, Stoboy H, Friedebold, Krivoy, Heyck, Van Riezen. Effect of ACTH peptide fragment on muscle action potentials. Lancet 1975; 2:919.

117 Wolters ECMJ, Leeuwin RS. Effect of corticosteroids on the phrenic nerve-diaphragm preparation treated with hemicholinium. A possible model of myasthenia gravis. Neurology (Minneap) 1976; 26:574-8. 
118 Wilson RW, Ward MD, Johns TR. Corticosteroids: a direct effect at the neuromuscular junction. Neurology (Minneap) 1974; 24:1091-5.

119 Hofmann WW. Antimyasthenic action of corticosteroids. Arch Neurol 1977; 34:356-60.

120 Rowland LP. Immunosuppressive drugs in treatment of myasthenia gravis. Ann NYAcad Sci 1971; 183:351-2.

121 Mertens HG, Balzereit F, Leipert M. The treatment of severe myasthenia gravis with immunosuppressive agents. Europ Neurol 1969; 2:323-39.

122 Hertel G, Mertens HG, Reuther P, Ricker K. The treatment of myasthenia gravis with azathioprine. In: Dau PC, ed. Plasmapheresis and the Immunobiology of Myasthenia Gravis. Boston: Houghton Mifflin, 1979: 315-28.

123 Matell G, Bergstrom K, Franksson C et al. Effects of some immunosuppressive procedures on myasthenia gravis. Ann NY Acad Sci 1976; 274:659-76.

124 Reuther P, Fulpius BW, Mertens HG, Hertel G. Antiacetylcholine receptor antibody under longterm azathioprine treatment in myasthenia gravis. In: Dau PC, ed. Plasmapheresis and the Immunobiology of Myasthenia Gravis. Boston: Houghton Mifflin, 1979: 329-50.

125 Newsom-Davis J, Vincent A, Wilson SG, Ward CD. Long-term effects of repeated plasma exchange in myasthenia gravis. Lancet 1979; 1:464-8.

126 Szobar A, Petranyi GY. Immunosuppressive therapy of myasthenia gravis. Acta Med Acad Sci Hungaricae 1970; 27:397-411.

127 Leovey A, Szegedi GY, Szobar A, Szathmary I, Petranyi GY. Myasthenia: ALG treatment of seriously ill patients. Eur Neurol 1975; 13: 422-32.

128 Pirofsky B, Reid RH, Bardana EJ Jr, Baker RL. Myasthenia gravis treated with purified antithymocyte antiserum. Neurology (Minneap) 1979; 29:112-6.

129 Behan PO. Combined plasma exchange and immunosuppression in myasthenia gravis. Lancet 1979; 2:741-2.

130 Smithers DW. Tumors of the thyroid gland in relation to some general concepts of neoplasia. J Faculty Radio 1959; 10:3-16.

131 Bergstrom K, Franksson C, Matell G, Von Reis G. The effect of thoracic duct lymph drainage in myasthenia gravis. Europ Neurol 1973; 9: 157-67.

132 Bergstrom K, Franksson C, Matell G et al. Drainage of thoracic duct lymph in 12 patients with myasthenia gravis. Europ Neurol 1975; 13:19-30.

133 Dunn JM. Neonatal myasthenia. Am J Obst Gyn 1976; 125:265-6.

134 Pinching AJ, Peters DK, Newsom-Davis JN. Remission of myasthenia gravis following plasma exchange. Lancet 1976; 2:1373-6.
135 Dau PC, Lindstrom JM, Cassel CK, Denys EH, Shev EE, Spitler LE. Plasmapheresis and immunosuppressive drug therapy in myasthenia gravis. N Engl J Med 1977; 297:1134-40.

136 Dau PC, Lindstrom JM, Cassel CK, Clark EC. Plasmapheresis in myasthenia gravis and polymyositis. In: Dau PC, ed. Plasmapheresis and the Immunobiology of Myasthenia Gravis. Boston: Houghton Mifflin, 1979: 229-47.

137 Howard JF Jr, Sanders DB, Johns TR. The role of plasma exchange therapy in myasthenia gravis. Presented at the Haemonetics Research Institute Advanced Component Seminar, June 1978.

138 Lisak RP, Schotland DL. Plasmapheresis in the treatment of myasthenia gravis. Trans $\mathrm{Am}$ Neurol Assoc 1978; 103:292-4.

139 Lisak RP, Abramsky O, Schotland DL. Plasmapheresis in the treatment of myasthenia gravis; preliminary studies in 21 patients. In: Dau PC, ed. Plasmapheresis and the Immunobiology of Myasthenia Gravis. Boston: Houghton Mifflin, 1979: 209-15.

140 Newsom-Davis J, Pinching AJ, Vincent A, Wilson SG. Function of circulating antibody to acetylcholine receptor in myasthenia gravis; investigation by plasma exchange. Neurology 1978; 28:266-272.

141 Newsom-Davis J, Ward CD, Wilson SG, Pinching AJ, Vincent A. Plasmapheresis: Short and long term benefits? In: Dau PC, ed. Plasmapheresis and the Immunobiology of Myasthenia Gravis. Boston: Houghton Mifflin, 1979: 199-208.

142 Behan PO, Shakir RA, Simpson JA, Burnett AK, Allan TL, Haase G. Plasma exchange combined with immunosuppressive therapy in myasthenia gravis. Lancet 1979; 2:438-40.

143 Olarte MR, Schoenfeldt R, Penn AS. Plasmapheresis in myasthenia gravis. In preparation.

144 Lindstrom JM, Seybold ME, Lennon VA, Whittingham S, Duane DD. Antibody to acetylcholine receptor in myasthenia gravis. Prevalence, clinical correlates, and diagnostic value. Neurology (Minneap) 1976; 26:1054-9.

145 Brenner T, Abramsky O, Lisak RP, Zweiman B, Tarrabl-Hazdai R, Fuchs S. Radioimmunoassay of antibodies to acetylcholine receptor in serum of mysthenia gravis patients. Israel $\mathrm{J} \mathrm{Med}$ Sci 1978; 14:986-9.

146 Vincent A, Newsom-Davis J. Absence of antiacetylcholine receptor antibodies in congenital myasthenia gravis. Lancet 1979; 1:441-2.

147 Twomey JJ, Lewis VM, Patten BM, Goldstein G, Good RA. Myasthenia gravis, thymectomy and serum thymic hormone activity. Am J Med 1979; 66:639-43.

148 Behan WMH, Behan PO. Immune complexes in myasthenia gravis. J Neurol Neurosurg Psychiatry $1979 ;$ 42:595-9. 